\section{Hipoglucemia intensa de ayuno secundaria a caquexia tuberculosa}

\section{Sr. Director:}

La hipoglucemia en pacientes no diabéticos tiene múltiples etiologías, pero rara vez un estado de caquexia comporta una hipoglucemia sintomática intensa, como en el caso que describimos. No hemos encontrado ninguna descripción similar en la bibliografía médica (MEDLINE, 1950-2003, palabras clave: hypoglycemia, cachexia, tuberculosis).

Un varón de 47 años ingresó por astenia, anorexia, tos y disnea en el último mes, constatándose infiltrados cavitados pulmonares bilaterales, con identificación de bacilos ácido-alcohol resistentes en el esputo. Un año antes ya fue diagnosticado de tuberculosis pulmonar y siguió tratamiento supervisado durante 6 meses con el esquema tradicional ( 2 meses isoniacida, rifampicina y piracinamida/4 meses isoniacida y rifampicina), por lo que se consideró que actualmente presentaba una recaída bacteriológica. Con posterioridad, el antibiograma mostró sensibilidad a todos los fármacos de primera línea. No tenía antecedentes de abuso de alcohol ni tomaba ninguna medicación. El paciente pesaba $39,5 \mathrm{~kg}$, la serología VIH fue negativa y la glucemia basal era de $77 \mathrm{mg} / \mathrm{dL}$. Se instauró tratamiento antituberculoso (2 meses isoniacida, rifampicina, piracinamida, etambutol/4 meses isoniacida, rifampicina, etambutol), que se continuó bajo supervisión en otro centro. Toleró bien la medicación, pero los cultivos de esputo seguían siendo positivos al finalizar el cuarto mes de tratamiento. Dado que perdía peso de forma progresiva, se procedió a suplementar la ingesta oral con nutrición enteral a través de sonda nasogástrica y fue remitido de nuevo a nuestro hospital para valoración. En la exploración física se constató: presión arterial $100 / 60 \mathrm{mmHg}$, temperatura $36,7^{\circ} \mathrm{C}$, peso $34,4 \mathrm{~kg}$, talla $152 \mathrm{~cm}$, caquexia intensa, ausencia de bocio, adenomegalias u organomegalias, estertores en ápices pulmonares y resto de exploración normal. En la analítica destacaba: hemoglobina 7,2 $\mathrm{g} / \mathrm{dL}$, plaquetas $604 \times 10^{9} / \mathrm{L}$, tiempo de protrombina $83 \%$, glucosa $23 \mathrm{mg} / \mathrm{dL}$, creatinina $0,17 \mathrm{mg} / \mathrm{dL}$, colesterol $77 \mathrm{mg} / \mathrm{dL}$, proteínas $5,6 \mathrm{~g} / \mathrm{dL}$, albúmina $2,4 \mathrm{~g} / \mathrm{dL}$, bilirrubina $0,3 \mathrm{mg} / \mathrm{dL}$, GGT $82 \mathrm{U} / \mathrm{L}$, AST $13 \mathrm{U} / \mathrm{L}$, ALT $10 \mathrm{U} / \mathrm{L}$, ferritina $559 \mathrm{ng} / \mathrm{mL}$, sodio 138,6 $\mathrm{mEq} / \mathrm{L}$, potasio $4,5 \mathrm{mEq} / \mathrm{L}$, tirotropina 3,01 $\mathrm{mU} / \mathrm{L}$ (normal hasta $5 \mathrm{mU} / \mathrm{L})$. En una tomografía computarizada (TC) torácica se apreciaron grandes cavitaciones en ambos lóbulos superiores y signos de diseminación broncógena. Durante el ingreso el paciente presentó episodios repetidos de hipoglucemias de ayuno con síntomas de neuroglucopenia, de los que se recuperaba lentamente tras la administración de glucosa intravenosa y glucagón. Esto obligó a mantener la nutrición enteral por sonda nasogástrica en infusión continua, a pesar lo cual las cifras de glucemia capilar oscilaban entre 50 y $60 \mathrm{mg} / \mathrm{dL}$. Se practicó una prueba de ayuno que tuvo que ser suspendida al cabo de 3 horas por coma hipoglucémico, durante la cual se constataron unos niveles plasmáticos de glucosa de $23 \mathrm{mg} / \mathrm{dl}$, insulina sérica $<7 \mathrm{pmol} / \mathrm{L}$ (normal de 40 a $110 \mathrm{pmol} / \mathrm{L}$ ) y péptido $\mathrm{C}<0,165 \mathrm{nmol} / \mathrm{L}$. El cortisol basal era de $555 \mathrm{nmol} / \mathrm{L}$ (normal de 221 a $780 \mathrm{nmol} / \mathrm{L}$ ), incrementando sus concentraciones hasta $753 \mathrm{nmol} / \mathrm{l}$ a los 30 minutos y hasta 875 $\mathrm{nmol} / \mathrm{L}$ a los 60 minutos de la administración de $250 \mathrm{mg}$ de ACTH por vía intravenosa. La detección de sulfonilureas en sangre fue negativa y la TC abdominal fue normal. Se consideró que el paciente padecía una tuberculosis activa, con fracaso farmacológico y caquexia secundaria. Después de la exclusión de otras causas a través de las pruebas complementarias mencionadas, atribuimos la hipoglucemia a la caquexia. Se remitió al paciente a una unidad de tuberculosis, donde falleció al cabo de 2 semanas. No se realizó autopsia.

El diagnóstico diferencial de una hipoglucemia de ayuno en el paciente adulto incluye: administración de agentes hipoglucemiantes, consumo excesivo de alcohol o de ciertas medicaciones (salicilatos, sulfamidas, quinina), tumores secretores de insulina (insulinoma), tumores productores de factores similares a la insulina (sarcomas, hepatomas), deficiencias de hormonas contrarreguladoras como los glucocorticoides (enfermedad de Addison), síndromes raros de hipoglucemia mediada por mecanismos inmunes (asociados a hiperinsulinemia) y comorbilidad grave como los estados de caquexia, sepsis, insuficiencia hepática avanzada, insuficiencia renal o insuficiencia cardiaca. En este último supuesto, la hipoglucemia se explicaría por la reducción de los depósitos de precursores gluconeogénicos como el glucógeno muscular y los aminoácidos glucogénicos.

Que el músculo esquelético es una importante fuente de sustratos gluconeogénicos durante el ayuno lo demuestra la predisposición de algunos pacientes con enfermedades neuromusculares como distrofias congénitas, atrofia muscular espinal o enfermedad de Duchenne, para desarrollar hipoglucemias (1-3). Los pocos casos descritos se acompañaban además de un bajo peso corporal, circunstancia que se asocia con depleción de los 
depósitos de glucógeno hepático. El caso que aportamos muestra que otras causas de atrofia muscular intensa, como la caquexia secundaria a una tuberculosis pulmonar, pueden potencialmente provocar hipoglucemias graves.

\section{A. B. Madroñero, J. M. Porcel}

Servicio de Medicina Interna. Hospital Universitario Arnau de Vilanova. Lleida

1. Orngreen MC, Zacho M, Hebert A, Laub M, Vissinng J. Patients with severe muscle wasting are prone to develop hypoglycemia during fasting. Neurology 2003; 61: 997-1000.

2. Shu S, Cruse RP, Redmon GP. Hypoglycemia in a child with congenital muscular dystrophy. Brain Dev 1989; 11: 62-5.

3. Bruce A, Jacobsen E, Dossing H, Kondrup J. Hypoglycemia in spinal muscular atrophy. Lancet 1995; 346: 609-10.

\section{Análisis de los costes derivados de la medicación antirretroviral durante los años 2002 y 2003 en un hospital del grupo 2}

\section{Sr. Director:}

La introducción de la terapia antirretroviral de gran actividad (TARGA), en el tratamiento de los enfermos afectos de infección por el virus de la inmunodeficiencia humana (VIH), ha mostrado un efecto altamente favorable, así se ha observado en los últimos años una dramática reducción en los índices de mortalidad hasta ahora presentes $(1,2)$.

Sin embargo debido a la reducción de la mortalidad y al aumento en el número de pacientes infectados, los gastos derivados del tratamiento antirretroviral se están incrementando progresivamente. El coste estimado derivado de la utilización de los medicamentos, analítica, personal sanitario y soporte psicosocial, se estima entre 12.000 y 20.000 dólares por paciente y año (3).

Sin embargo, hay que matizar con respecto a los gastos sanitarios, que éstos son claramente diferentes según los distintos estadios de la infección, así en el estadio A (paciente asintomático), la media de los costes anuales asciende a 2.373 dólares, en el estadio B de 8.401 dólares y en el estadio C de 23.373 dólares. Por supuesto, la partida más importante implica a los gastos derivados de la hospitalización (4), que ha seguido una tendencia claramente descendente en los últimos años, por lo que coste global no se ha aumentado, pese al incremento de los gastos derivados de los pacientes atendidos en las consultas externas (5).

Los nuevos fármacos tienen en muchas ocasiones un precio más elevado, lo que incrementa a su vez el coste derivado de su utilización (6).

Hemos decidido presentar los resultados de un pequeño estudio en el que analizábamos los costos directos derivados de la utilización de medicación antirretroviral durante los años 2002 y 2003, en una consulta monográfica de VIH en un hospital del grupo 2, para comprobar el presumible incremento del coste farmacéutico derivado del número cada vez más elevado de enfermos incluidos en programas de tratamiento antirretroviral. A su vez queríamos comprobar qué fármacos de cada grupo eran los más utilizados y el coste derivado de los mismos.
En el año 2002, un total de 60 enfermos recibieron tratamiento antirretroviral, el gasto ocasionado por la utilización de análogos de nucleósidos inhibidores de la transcriptasa inversa (ANITI), fue de 184.845 euros, correspondiendo a la asociación combivir (zidovudina y estavudina ) con 62.000 euros y trizivir ( zidovudina, estavudina y abacavir) con 37.916 euros, seguido de estavudina con 35.510 euros, los fármacos que originaron el mayor coste. El gasto derivado de la utilización de no análogos de nucleósidos inhibidores de la transcriptasa inversa (NNITI), fue de 70.600 euros, correspondiendo el mayor gasto a la nevirapina con 47.302 euros. Finalmente el gasto derivado de la utilización de los inhibidores de proteasa (IP), ascendió a 69.000 euros, correspondiendo el mayor gasto al nelfinavir con 30.000 euros, seguido del lopinavir/ritonavir con 11.830 euros.

El coste total por la utilización de medicación antirretroviral en el año 2002 ascendió a un total de 324.454 euros, lo que significa un gasto por paciente y año de 5407,5 euros.

En el año 2003, un total de 69 pacientes recibieron tratamiento con fármacos antirretrovirales ( por lo tanto el incremento en el número de enfermos fue del $15 \%$ ). Analizando por grupos, el coste derivado de la utilización de ANITI fue de 177.156 euros, correspondiendo el mayor gasto a la combinación de zidovudina y estavudina (combivir) con 63.658 euros, seguido de la asociación trizivir, con un total de 32.404 euros y de estavudina con 29.881 euros. El coste derivado de la utilización de NNITI fue de 71.782 euros, destacando nevirapina con 39.474 euros. El coste derivado de la utilización de IP, fue de 72.464 euros, destacando nelfinavir con 41.111 euros y lopinavir/ritonavir con 18.871 euros. Durante el año 2003 se introdujo en el tratamiento de nuestros enfermos, un fármaco nuevo, nucleótido inhibidor de la transcriptasa inversa- NITI, tenofovir, con un coste de 32.323 euros.

El coste total derivado de la utilización de medicación antirretroviral durante el año 2003, ascendió a un total de 353.725 euros, lo que representa un gasto por paciente y año de 5126,45 euros, existiendo una reducción de los costes por paciente y año de 281,11 euros. Con respecto al año 2002, el coste del consumo del tratamiento por antirretrovirales se incrementó en 29.271 euros, pero teniendo en cuenta que el número de enfermos en tratamiento en la consulta de VIH fue de 9 pacientes más, hemos conseguido un ahorro neto total de 19.396 euros, resultado de multiplicar 281,11 x 69 enfermos en tratamiento en la actualidad.

La explicación de este ahorro puede deberse a los programas de simplificación del tratamiento antirretroviral, a los programas de interrupción del tratamiento antirretroviral, cuando se había iniciado siguiendo unos criterios diferentes a los admitidos en la actualidad, fundamentalmente en los enfermos en los que se inició con más de $350 \mathrm{CD} 4$, en ocasiones cercanos a 500, siguiendo criterios de carga viral, y que durante el seguimiento no hubieran presentado ninguna complicación de la infección y en algún caso a interrupciones del tratamiento durante unos meses, por toxicidad metabólica severa.

\section{F. Marcos Sánchez, I. Albo Castaño, F. Árbol Linde, D. Joya Seijo, P. del Valle Loarte}

Servicio de Medicina Interna. Hospital Nuestra Señora del Prado. Talavera de la Reina. Toledo.

1. Hogg RS, Weber AE, Craib KJP, Anis AH, O'Shaughnessy MV Schechter MT, et al. One word, one hope: the cost of providing antiretroviral therapy to all nations. Aids 1998; 12: 2203-2209.

2. Kyriopoulos JE, Geitona MA, Paparizos VA, Kyriakis KK, Botsi CA, Stavrianeas NG. The impact of new antiretroviral therapeutic schemes on the cost for AIDS treatment in Greece. J Med Syst 2001; 25: 73-80.

3. Binswanger HP. HIV/AIDS treatment for millions. Science 2001; 292: 221-223. 
4. Decock RC, Depoorter AM, De Graeve D, Colebunders R. Direct costs of health care for HIV/AIDS patients in Belgium. AIDS Care 2001; 13: 721-730.

5. Anonymus. Cost decline with HAART. AIDS Patient Care STDS 2000; 14: 672.

6. Steinbrook R. HIV infection- a new drug and new costs. N Engl J Med 2003; 348: 2171-2172.

\section{Utilidad de las extensiones de sangre periférica en sepsis meningocócicas}

\section{Sr. Director:}

Presentamos dos casos de sepsis en dos adolescentes de 15 y 14 años respectivamente. En el primer caso (paciente 1), un joven de 15 años acude al Servicio de Urgencias de nuestro hospital con pérdida de consciencia, vómitos, fiebre $\left(40{ }^{\circ} \mathrm{C}\right)$, incontinencia urinaria y fecal, y múltiples petequias diseminadas en brazos y tronco. No se encuentra foco neurológico ni ningún otro síntoma de inflamación meningea. El estudio radiográfico, la tomografía axial realizada y el estudio del líquido cefalorraquídeo resultan normales (aspecto claro, glucosa $60 \mathrm{mg} / \mathrm{dL}$, proteínas $24,4 \mathrm{mg} / \mathrm{dL}$, ADA 5.2 U/L, tinciones de Gram y naranja de acridinina negativas). Se aprecia leucocitosis $\left(16,5 \times 10^{9}\right.$ leucocitos/L) con desviación izquierda, y la visión de la extensión de sangre periférica revela la presencia de diplococos tanto extracelulares como en el interior de los leucocitos polimorfonucleares (Fig. 1), que también fueron observados en tinciones de Gram y naranja de acridina realizadas en sangre periférica.

En el segundo caso (paciente 2), otro adolescente de 14 años ingresa en el Servicio de Urgencias refiriendo malestar general, dolor de garganta, vómitos diarrea, fiebre $\left(38,3^{\circ} \mathrm{C}\right)$, y la presencia de petequias diseminadas. Se aprecia cianosis $(\mathrm{pH}$ arterial 7.117) con valores normales de leucocitos de $6,4 \times 10^{\circ} / \mathrm{L}(73,9 \%$ PMN) y en las extensiones de sangre periférica realizadas, al igual que en las tinciones de Gram y naranja de acridina, se observan diplococos extra e intracelulares. Se extrae muestra de sangre para hemocultivo.

Caso 1: se procesa muestra de sangre para cultivo, y se administran al paciente vancomicina y ceftriaxona vía $i v$. 24 horas más tarde, el paciente desarrolla fallo hemodinámico, fallo renal con

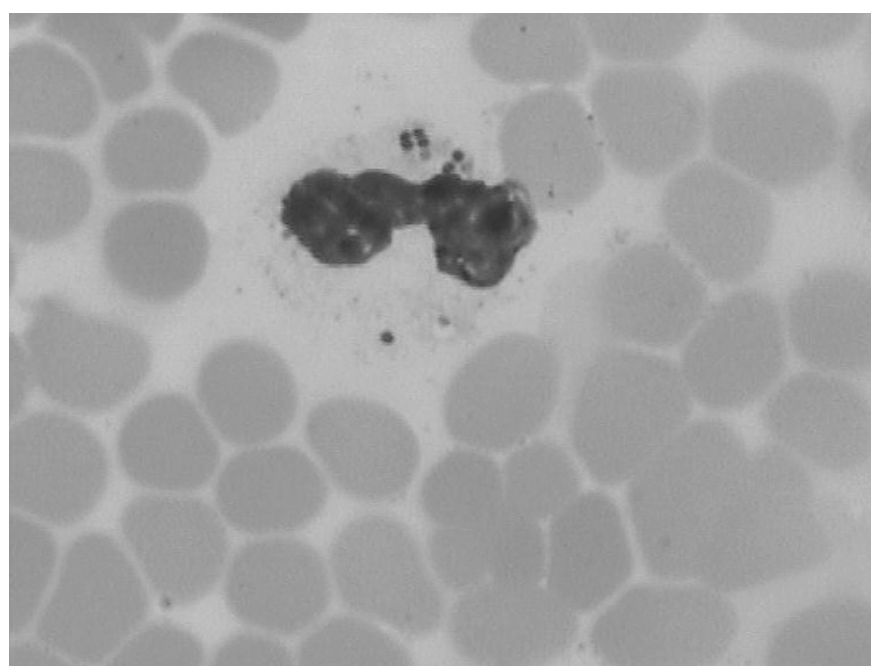

Fig. 1. anuria, fallo respiratorio, importante coagulopatía por consumo y severa trombopenia. Días después se practicó amputación infracondilea de las dos piernas y de varias falanges de ambas manos. El diagnóstico inicial fue de shock séptico y sepsis meningocócica (N. meningitidis serogrupo C aislado del hemocultivo) sin meningitis.

Caso 2: trasladado inmediatamente a la Unidad de Cuidados Intesivos, fallece en menos de 2 horas desde la llegada a nuestro centro. La evolución sugiere una sepsis fulminante, probablemente meningocócica. Un día después del fatal desenlace y pese a no obtener crecimiento en los frascos de hemocultivo, se detectó antígeno de $N$. meningitidis serogrupo C. Este hallazgo fue confirmado posteriormente por estudio PCR en muestras de suero y sangre periférica enviadas al Centro Nacional de Microbiología.

A pesar de los avances en la atención y los tratamientos en Servicios Hospitalarios como Urgencias y Cuidados Intensivos, seguimos encontrando unas morbilidad y mortalidad elevadas asociadas a sepsis meningocócicas y púrpuras fulminantes (1). La conjunción de técnicas ordinarias tan sencillas y frecuentes en un Laboratorio de Urgencias como la tinción clásica de Giemsa en sangre periférica, y las técnicas microbiológicas tanto clásicas (tinciones de Gram, naranja de acridina,...) como las más novedosas (PCR), puede aún hoy día ayudar no sólo a la emisión de un rápido diagnóstico presuntivo (2) sino incluso a reducir los índices de mortalidad en patologías tan agresivas como la descrita.

\section{J. Ferrer Cañabate, J. M. Zarauz García, A. Periago Peralta, C. Cava Almohalla, L. C. Alberola}

Servicio de Análisis Clínicos. Hospital Rafael Méndez. Lorca. Murcia

1. Warner PM, Kagan RJ, Yakuboff KP, et al. Current management of purpura fulminans: a multicenter study. J Burn Care Rehabil 2003; 24 (3): 119-26

2. Rumi E, Astori C, Casazza A, Marone P and Bonfichi M. Peripheral intraneutrophil diplococci in a case of meningococcemia. Haematologica 2004; 89 (4): EIM05

Síndrome confusional agudo asociado a la infección de un dispositivo intravascular

\section{Sr. Director:}

La incidencia de infección de dispositivos intravasculares, materiales sintéticos protésicos, es del 1 al 5\%, siendo menor a nivel de aorta e ilíacas (1\%) y mayor cuando se atraviesa la región inguinal, a nivel aorto-femoral o femoro-poplítea (2-5\%). La infección se suele producir intraoperatoriamente, por extensión desde los tejidos adyacentes (puede protegerse realizando ligamiento de los linfáticos) o por siembra hematógena (1). Los gérmenes más frecuentes son el Stapylococcus aureus (25-35\% de las prótesis infectadas) y los Staphylococcus coagulasa negativos, siendo polimicrobianas en el 12-37\%. El tiempo medio que transcurre desde la intervención es de unos 10 meses. La clínica dependerá de la zona anatómica implicada, apareciendo además datos que reflejan una infección indolora como fiebre intermitente, mal estado general y/o pérdida de peso. Así si la clínica local 
es escasa o nula, dado que los síntomas generales son tan inespecíficos la sospecha diagnóstica es fundamental.

Varón de 77 años, con antecendentes personales de exfumador, diabetes mellitus tipo 2, fibrilación auricular paroxística, gastrectomía parcial e isquemia crónica de extremidades inferiores grado IV. Nueve meses antes de este ingreso (abril-02) ingresó por un pie diabético con infección por Staphylococcus aureus meticilín sensible, tratado con amoxicilina-clavulánico y clindamicina durante 6 días, retirado por exantema; realizándose posteriormente (a los 15 días) un puente femoropoplíteo izquierdo con Gore te $\mathrm{x}^{\circledR}$ y simpatectomía lumbar izquierda. Reingresó en cirugía vascular dos meses después (junio-02) con el diagnóstico al alta de síndrome postrombótico y celulitis inespecífica, tratado con amoxicilina-clavulánico 500/125 mg cada 8 horas vía oral. Un mes después (julio-02) ingresó en neurología por deterioro general con dificultad para la marcha y alteraciones de la conducta, según la familia desde la intervención quirúrgica, con importante agitación nocturna y alucinaciones visuales ocasionales. Durante ese ingreso presentó fiebre que fue achacada a una infección urinaria y tratada con amoxicilina-clavulánico. Tras estudio serológico, analítico y de neuroimagen se detectó leve atrofia cortico-subcortical y un déficit de vitamina $\mathrm{B}_{12}$ iniciándose tratamiento sustitutivo enviando al paciente a su domicilio. Al ingreso en nuestra planta destacaba el cuadro confusional, sin focalidad neurológica aparente, sin datos exploratorios generales relevantes. Analíticamente el hemograma y la bioquímica estaban en rangos normales, destacando una elevación de la velocidad de sedimentación y de las alfa 2 globulinas. A las 24 horas presentó pico febril, extrayéndose 2 hemocultivos e iniciándose tratamiento empírico con cefepime $1 \mathrm{~g} / 8$ horas. Posteriormente el servicio de Microbiología nos informó de la positividad de ambos hemocultivos con crecimiento de $S$. aureus, modificando la antibioterapia. Tras revisar la historia clínica y teniendo en cuenta que el cuadro actual apareció tras la intervención quirúrgica y la infección, previa a la cirugía, en la extremidad intervenida por el mismo germen, se realizaron una tomografía axial computerizada (TAC) y una gammagrafía con leucocitos marcados, que confirmaron la infección de la prótesis. Se realizaron una TAC cerebral y un ecocardiograma transtorácico descartando complicaciones. Valorado por el servicio de Cirugía Vascular se decidió traslado a su servicio para plantear tratamiento definitivo. El paciente mejoró, con el tratamiento antibiótico, de forma muy importante, recobrando su estado neurológico normal y su autonomía previa. Al paciente se le propuso la retirada del puente infectado con restitución de la circulación mediante interposición de puente autólogo venoso o biológico, rechazándolo, decidiendo tratamiento con cloxacilina oral. A los dos meses se realizó eco-doppler apreciando dilatación fibrosa periprotésica en tercio superior-medio y en la zona de anastomosis distal terminal y nueva gammagrafía persistiendo los focos sobre línea del trayecto vascular.

El diagnóstico, además de si existe clínica de infección local, se debe realizar mediante estudios radiológicos para demostrar las alteraciones anatómicas o la inflamación periprotésica: TAC, resonancia magnética (2), ecografía (limitada) y gammagrafía con leucocitos marcados (sensible y específica). En un 50\% existe bacteriemia. El tratamiento consiste en antibioterapia las primeras 4-6 semanas y cirugía. La mortalidad es del $17-20 \%$ y la amputación es necesaria en el 20-25\%. La gammagrafía con leucocitos marcados a los 30 minutos y a las 24 horas, demuestra un incremento patológico de la captación persistente sobre el área protésica; existen estudios comparativos entre TAC y gammagrafía concediendo, a esta última, una sensibilidad del $100 \%$ y una especificidad del 95\% $(3,4)$. Dado que se trata de una septicemia, además de la clínica de infección local (en ocasiones muy escasa) aparecen manifestaciones como los estados confusionales, siendo muy difícil orientar el caso salvo que los antecendentes estén bien recogidos en la historia clínica y el grado de sospecha sea alto.

\section{Toyas Miazza, R. Ortas Nadal, E. Prats Rivera ${ }^{1}$, B. Redal Baigorri}

Servicio de Medicina Interna y de ${ }^{\prime}$ Medicina Nuclear. Hospital Clínico Universitario Lozano Blesa. Zaragoza

1. Chang JK, Calligaro KD, Ryan S, Runyan D, Dougherty MJ, Stern JJ. Risk factors associated with infection of lower extremity revascularization: analysis of 365 procedures performed at a teaching hospital. Ann Vasc Surg 2003; 17: 91-6.

2. Orton DF, LeVeen RF, Saigh JA, Culp WC, Fidler JL, Lynch TJ, et al, McCowan TC. Aortic prosthetic graft infections: radiologic manifestations and implications for management. Radiographics 2000; 20: 977-93.

3. Prats E, Liberatore M, Razola P, Delgado M, García F, Rizzo L, et al 99mTc-HMPAO-labelled leucocyte scan and CT in the diagnosis of vascular grafo infección. En: Signore A, Liberatore M, Scopinaro F editors. Nuclear Medicine in the management of inflamatory and infectious diseases. Berlin: Springer, 2003: 128-134.

4. Prats E, Banzo J, Abos MD; García-López F, Escalera T, García-Miralles $\mathrm{M}$, et al. Diagnostic of prosthetic vascular graft infection by technetium99m-HMPAO-labeled leukocytes. J Nucl Med 1994; 35: 1303-7.

\section{Peritonitis bacteriana espontánea como forma de debut de adenocarcinoma de colon}

\section{Sr. Director:}

La peritonitis bacteriana espontánea (PBE) se caracteriza por la infección del líquido ascítico sin evidencia de un foco infeccioso abdominal. Es una complicación frecuente en pacientes con ascitis de origen cirrótico (8-10\%) (1). Se ha descrito asociada a ascitis de etiología no cirrótica en enfermos con síndrome nefrótico, y de forma excepcional, en la ascitis tumoral (1-3). Las escasas publicaciones realizadas sobre la aparición de PBE en pacientes con ascitis de etiología neoplásica, consideran necesaria la existencia previa de hipertensión portal previa (HTP) (3). Presentamos un caso de peritonitis bacteriana espontánea en paciente con ascitis secundaria a adenocarcinoma de colon.

Varón de 72 años, con antecedentes personales de diabetes mellitus tipo 2, fumador con enfermedad pulmonar obstructiva crónica y accidente cerebrovascular seis años antes con parestesias residuales en la mano izquierda. No refería ingesta de alcohol. Seguía tratamiento habitual con Glibenclamida, Bromuro de ipratropio y Ácido acetil salicílico. Consulta por dolor abdominal generalizado, con alteración del hábito intestinal, vómitos postpandriales, aumento del perímetro abdominal y síndrome constitucional de dos meses de evolución. No refería fiebre, disminución de diuresis, aumento del perímetro en miembros inferiores, ni rectorragia. En la exploración destacaba temperatura de 37,8 ${ }^{\circ} \mathrm{C}$, con deterioro del estado general, no presentaba datos de hepatopatía crónica, ingurgitación yugular ni adenopatías periféricas, abdomen levemente doloroso a la palpación generalizada con semiología de ascitis, extremidades sin edemas ni datos de flebitis. En la analítica destacaba hemograma con 25.600 leucocitos $/ \mathrm{mm}^{3}$ (88\% segmentados), Hb 9,7 g/dL, Hto 29\%, VCM $90 \mathrm{fL}$, $548.000 / \mu \mathrm{L}$ plaquetas, coagulación con actividad de protrombina $100 \%$, aPTT 29 segundos, bioquímica con urea $44 \mathrm{mg} / \mathrm{dl}$, creatinina $0,9 \mathrm{mg} / \mathrm{dl}$, bilirrubina total $0,65 \mathrm{mg} / \mathrm{dl}$, AST $17 \mathrm{UI} / \mathrm{L}$, ALT 9 UI/L, GGT $50 \mathrm{UI} / \mathrm{L}$, amilasa $86 \mathrm{UI} / \mathrm{L}$, LDH $1315 \mathrm{UI} / \mathrm{L}$, fosfatasa alcalina $117 \mathrm{UI} / \mathrm{L}$. Proteinograma con proteínas totales 5,7 g/dl, albúmina 2 g/dl, Ig G 610 mg/dl, Ig M 425 mg/dl, PCR 43 mg/dl, 
fracciones del complemento C3 y C4 normales. Hormonas tiroideas normales. Autoanticuerpos ANA, anti DNA, antiVHC, HBsAg y HBcIgM negativos. Los valores de alfa-feto proteína y PSA fueron normales, los de CA 19,9 mayores de $500 \mathrm{U} / \mathrm{ml}$ (normal < 37) y los de CEA $80 \mathrm{ng} / \mathrm{ml}($ normal < 5 ). Se realizó paracentesis de líquido ascítico, en el análisis bioquímico se encontraron 2.300 hematíes $/ \mathrm{mm}^{3}, 4.800$ leucocitos $/ \mathrm{mm}^{3}(70 \%$ polimorfonucleares), glucosa $104 \mathrm{mg} / \mathrm{dl}$, ADA $40 \mathrm{UI} / \mathrm{ml}, \mathrm{LDH}$ $673 \mathrm{UI} / \mathrm{L}$, proteínas totales 3,4 g/dl, albúmina 2,09 g/dl, gradiente albúmina sérica - líquido ascítico menor de 1 . La tinción para bacilos ácido-alcohol resistentes, el análisis de ADN para Mycobacterium Tuberculosis y la citología para células tumorales malignas fueron informadas como negativas. El cultivo fue positivo para Bacteroides sp., se realizó tratamiento según antibiograma con resolución del cuadro de peritonitis.

En la TC toraco-abdominal con contraste, se describieron dos imágenes pseudonodulares puntiformes inespecíficas en los lóbulos superior e inferior del hemitórax derecho, ascitis masiva con peritoneo parietal visible y realzado y aumento de densidad en el omento mayor sugestiva de infiltración tumoral; en bazo e hígado no se encontraron alteraciones significativas. La gastroscopia realizada no mostró hallazgos. En la colonoscopia se observó mucosa de aspecto pseudopolipoide, neoformativa de $3 \mathrm{cms}$ de extensión localizada a $10 \mathrm{~cm}$ del margen anal. Se tomó biopsia de la zona, cuyo informe anatomopatológico fue de adenocarcinoma de intestino grueso.

El paciente fue diagnosticado de adenocarcinoma de colon con peritonitis bacteriana espontánea. Tras ser valorado por oncología y teniendo en cuenta la extensión tumoral, se decidió realizar tratamiento paliativo quimio-radioterápico.

La peritonitis bacteriana espontánea se define por la infección del líquido ascítico con cultivo positivo y recuento elevado de leucocitos polimorfonucleares $\left(>=250\right.$ céls $\left./ \mathrm{mm}^{3}\right)$, sin que exista una causa intraabdominal tratable quirúrgicamente (4-7). El criterio más importante es la elevación del número de leucocitos, con una especificidad diagnóstica del 85-91\% (4). El cultivo suele ser monomicrobiano. Los patógenos más frecuentemente aislados son Escherichia coli, Klebsiella pneumoniae, Streptococcus pneumoniae y Estafilococo sp. Los anaerobios se aíslan sólo en el $1 \%$ de los casos $(2,6)$. La patogenia se relaciona con el sobrecrecimiento de la flora intestinal y su diseminación por vía linfática y hematógena, junto a la alteración en la función del sistema mononuclear-fagocítico (2).

Las manifestaciones clínicas más frecuentes son fiebre, dolor abdominal y estado confusional. Puede cursar con encefalopatía, aumento de ascitis previa ó deterioro de la función hepática. La complicación más habitual es el síndrome hepatorrenal, el cual ocurre en el $30 \%$ de los casos y ocasiona una elevada mortalidad $(6,7)$.

La existencia de ascitis previa es indispensable para el desarrollo de PBE. La carcinomatosis peritoneal es el principal mecanismo de producción de la ascitis de origen tumoral, se suele deber a neoplasias de colon, estómago u ovario que infiltran el peritoneo. Otras veces, se produce por hipertensión portal secundaria a metástasis hepáticas u obstrucción de venas suprahepáticas, y a la obstrucción o rotura de linfáticos (8).

Los casos publicados de PBE en ascitis neoplásica, coinciden en señalar lo excepcional de esta presentación $(1,3)$. Kurt et al. realizaron una revisión de 101 pacientes que habían presentado ascitis neoplásica. Sólo encontraron tres casos con cultivo positivo en el líquido ascítico. Sin embargo, tras realizar un análisis detallado se demostró que ninguno cumplía criterios de PBE. En dos de ellos existían factores iatrógenos previos y el tercer paciente presentaba una sepsis generalizada (1).

Posteriormente, Bac et al. analizaron 60 casos de PBE diagnosticados en un período de cinco años. Sólo en dos pacientes, la infección del líquido ascítico se había producido en el contexto de ascitis de etiología neoplásica. Tras realizar una revisión de la literatura, estos autores afirman que la PBE asociada a ascitis tumoral aparece exclusivamente en pacientes con hipertensión portal previa, probablemente debida a la existencia de metástasis hepáticas masivas ó trombosis portal . Por este motivo, se consideró que era un requisito indispensable para el desarrollo de la infección ${ }^{3}$. La HTP se suele acompañar de una baja concentración de proteínas en el líquido ascítico y de los niveles de complemento, lo que favorece que se produzca la infección al descender la capacidad de opsonización y eliminación bacteriana (2).

Sin embargo, nuestro paciente no presentaba ninguno de los factores de riesgo habituales para el desarrollo de PBE. No se demostró hipertensión portal, descenso de proteínas en el líquido ascítico, alteración de la función hepática, episodios anteriores similares, ni había precisado colocación de catéteres previos. A pesar de lo cual, desarrolló PBE como primera manifestación de la neoplasia subyacente. Por tanto, esto nos hace considerar que la HTP no es una condición indispensable para que se produzca la infección del líquido ascítico, pudiendo aparecer en pacientes que no la presentan, aunque de forma excepcional como sucedió en nuestro caso.

\section{D. Mañas García, E. Marchán Carranza, F. Ceres Ala- bau, J. Gijón Rodríguez}

Servicio de Medicina Interna. Complejo Hospitalario. Ciudad Real

1. Kurtz RC, Bronzo RL. Does spontaneous bacterial peritonitis occur in malignant ascites? Am J Gastroenterol 1982; 77: 146-8.

2. Runyon BA. Pathogenesis of spontaneous bacterial peritonitis. In UpToDate 11.3, Rose BD (Ed), UpToDate, Wellesley, MA, 2003.

3. Bac DV, de Marie S, van Blankenstein M. Spontaneous bacterial peritonitis complicating malignancy-related ascites. Dig Dis Sci 1996; 41: 131-2.

4. Wang SS, Lu CW, Chao Y, Lee My, Lin HC, Lee SD, et al. Malingnancy-related ascites: a diagnostic pitfall of spontaneous bacterial peritonitis by ascitic fluid polymorphonuclear cell count. J Hepatol 1994; 20: 79-84.

5. Runyon BA. Diagnosis of spontaneous bacterial peritonitis. In UpToDate 11.3, Rose BD (Ed), UpToDate, Wellesley, MA, 2003.

6. Atención del paciente con ascitis. En: Yamada T, editor. Manual de Gastroenterología. Spain 2000; p. 158-159.

7. Ginés P, Cárdenas A, Arroyo V, Rodés J. Management of cirrosis and ascites. N. Engl J Med 2004; 350: 1646-1654.

8. Runyon BA, Hoefs JC, Morgan TR. Ascitis fluid analysis in malignancyrelated ascites. Hepatol 1988; 8: 1104-1109.

\section{Hipotiroidismo y miositis por lovastina}

\section{Sr. Director:}

Existe una estrecha relación entre hipotiroidismo, hipercolesterolemia y toxicidad por estatinas. Por una parte el hipotiroidismo puede producir elevación de cifras de creatincinasa (CK) e hipercolesterolemia (1-3). De hecho se ha visto que en una consulta de lípidos la prevalencia de hipotiroidismo es el doble que en una consulta general (4). Además es una causa de falta de respuesta al tratamiento con hipolipemiantes (5). Por otra parte el hipotiroidismo incrementa el riesgo de toxicidad por estatinas $(1,2)$. La asociación de hipotiroidismo y toxicidad muscular por estatinas ha sido descrita en pacientes tratados con sinvastatina, cerivastatina y pravastatina $(3,5,6)$, pero en nuestro conocimiento 
no con lovastatina. Presentamos el caso de una paciente con hipotiroidismo no conocido que debutó como miositis por lovastatina.

Mujer de 73 años hipertensa y diabética a tratamiento crónico con amlodipino, valsartán, indapamida, glicacida. En los últimos 2 meses tomaba también lovastatina ( $20 \mathrm{mg} /$ día) por la detección de hipercolesterolemia. La paciente relataba un cuadro de un año de evolución de astenia y estreñimiento. En los últimos dos meses la astenia era más intensa y se acompañaba de debilidad y dolor en ambas piernas. En la exploración física no presentaba ningún dato relevante. En la analítica destacaba: mioglobina: 341 ng/mL (0-75), CK: 1082 UI/L (1-110), GOT: 36 UI/L (0-25), GPT: $31 \mathrm{UI} / \mathrm{L}$ (0-29), Cr: 1,7 mg/dL. Tras suspender la lovastatina la evolución fue favorable con descenso de cifras de CK aunque sin llegar a normalizarse (CK: $377 \mathrm{UI} / \mathrm{L})$. En el resto de estudios realizados se detectó: TSH: 180 Mui/L (0,35-5,50), T3: 0,07 $\mathrm{pg} / \mathrm{mL}(2,30-4,20)$, T4: $0,24 \mathrm{ng} / \mathrm{dL}(0,89-1,80)$, Acs anti TPO: $740 \mathrm{UI} / \mathrm{Ml}(0-33)$ y colesterol total: $377 \mathrm{mg} / \mathrm{dL}$ (120-254). Se inició tratamiento con levotiroxina con normalización de cifras de CK y de colesterol.

Las estatinas son fármacos muy usados en el tratamiento de las hipercolesterolemias $(1,2)$. Son seguros aunque entre los efectos secundarios más conocidos se encuentra la toxicidad muscular (7). Recientemente se ha propuesto la clasificación en cuatro síndromes del daño muscular por estatinas: miopatía (cualquier alteración muscular relacionada con los fármacos), mialgia (síntomas musculares sin elevación de CK), miositis (síntomas musculares con elevación de CK) y rabdomiolisis (elevación de CK superior a 10 veces el límite normal, con elevación de las cifras de creatinina debido a nefropatía por mioglobina) (1). Sin embargo, la terminología utilizada en los estudios publicados hasta el momento no es homogénea, lo que dificulta cuantificar la incidencia real de cada uno de estos cuadros. La elevación leve y asintomática de las cifras de CK es según distintos autores la forma más frecuente $(1,2)$. La rabdomiolisis es la complicación más grave pero menos frecuente; la incidencia de rabdomiolisis fatal es de 0,15 muertes/ millón de prescripciones $(1,2)$, sin que se haya visto diferencias significativas entre las diferentes estatinas comercializadas actualmente. Entre el 1-5\% de pacientes presentan mialgias sin elevación enzimática y en algunos de ellos se objetivaron datos de disfunción mitocondrial en la biopsia muscular (1). La aparición de síntomas musculares con elevación de CK inferior a 10 veces el límite normal (englobado dentro del término miositis) ha sido reportado en 49 de 42.323 pacientes tratados con estatinas $(0,11 \%)$ frente a 44 de 41.535 tratados con placebo $(0.10 \%)$ (1). En el caso concreto de la lovastatina únicamente en un estudio se recoge la incidencia de miositis sin encontrar diferencias respecto a placebo $(0,63 \%$ en ambos grupos) (1).

Hay diversos factores que incrementan el riesgo de toxicidad, entre los que se encuentra el uso concomitante de fármacos que inhiban el citocromo P450, la insuficiencia hepática, la insuficiencia renal, el hipotiroidismo, la diabetes y la edad avanzada (1, $2,7)$. Esta paciente presentaba los últimos cuatro lo cual multiplicaba el riesgo de toxicidad. Además lo más probable es que la hipercolesterolemia estuviese en relación con el hipotiroidismo no diagnosticado. De hecho eso explicaría perfectamente la astenia y el estreñimiento que presentaba así como la persistencia de la hipercolesterolemia a pesar del tratamiento hipolipemiante. Por otra parte la cifra de CK no se normalizó tras suspender la lovastatina sino una vez instaurado el tratamiento con levotiroxina. Al igual que en este caso, las cifras de colesterol pueden descender una vez tratado el hipotiroidismo y no ser necesario el uso de estatinas. Esto suele ocurrir cuando el valor de TSH es mayor de 10 Mui/L (4).

Por tanto ante un paciente con hipercolesterolemia es conveniente realizar un despistaje de hipotiroidismo tanto porque puede ser la causa de la misma como porque aumenta el riesgo de toxicidad por estatinas. La asociación entre hipotiroidismo y mio- sitis por estatinas ya había sido descrita con la simvastatina, cerivastatina y pravastatina $(3,5,6)$ pero no con la lovastatina.

\section{Rodríguez Framil, C. Martínez Rey, M. R. Alende Sixto, J. A. Torre Carballada}

Servicio de Medicina Interna. Hospital Clínico Universitario. Santiago de Compostela, A Coruña

1. Thompson PD, Clarkson P, Karas RH. Statin-associated myopathy. JAMA 2003; 289 (13): 1681-90.

2. Pasternak RC, Smith SC, Balrey-Merz CN, Grundy SM, et al. ACC/AHA/NHLBI clinical advisory on the use and safety of statins. J Am Coll Cardiol 2002; 40: 567-572.

3. Hung YT, Yeung VT. Hypothyroidism presenting as hypercholesterolemia and simvastatin-induced myositis. Hong Kong Med J 2000; 6 (4): 219-20.

4. Dieckman T, Lansberg PJ, Kastelein JJ, Wiersinga WM. Prevalence and correction of hypothyroidism in a large cohort of patients referred for dyslipidemia. Arch Intern Med 1995; 155 (14): 1490-5.

5. Polo Romero FJ, Beato Pérez JL. Hipercolesterolemia, rhadomyolysis and hypothyroidism. Rev Clin Esp 2003; 203 (3): 236-7.

6. Pía Iglesias G, Garrido Sanjuán JA, González González C, Sesma Sánchez P. Antilipemic agents, hypothyroidism and rhadbomyolysis. Rev Clin Esp 2000 (4): 236-7

7. Capella D, Bosch M. Statins: benefit or risk? Med Clin (Barc) 2002; 118 (9): 335-6.

\section{Hidrotórax hepático}

\section{Sr. Director:}

Contamos el caso de un paciente varón de 69 años que había sido diagnosticado de cirrosis hepática por virus $\mathrm{C}$, como resultado de una descompensación hidrópica inicial. Dos años después el paciente volvió a ingresar con una peritonitis bacteriana espontánea $(\mathrm{PBE})$, moderada cantidad de ascitis y derrame pleural masivo en hemitórax derecho. Se le realizó una toracocentésis obteniendo un líquido de aspecto seroso en el que el análisis bioquímico mostró que tenía características de transudado. Posteriormente se realizó una gammagrafía con macroagregados de albúmina que demostró la existencia de una comunicación pleuroperitoneal (Fig. 1). Se comenzó tratamiento con antibióticos y diuréticos pero el paciente presentó una insuficiencia renal prerenal y no se redujo el derrame pleural requiriendo toracocentesis evacuadoras de repetición que empeoraban la situación. Debido a la dificultad de control de sus síntomas se decidió la colocación de un TIPS (shunt portosistémico intrahepático transyugular). Dicha técnica se realizó sin complicaciones, mejorando la diuresis del paciente y normalizándose la cifra de creatinina sérica. También se produjo una reducción evidente del derrame pleural y de sus síntomas respiratorios.

El hidrotórax hepático se define como la presencia de derrame pleural en un paciente cirrótico en ausencia de enfermedad primaria pulmonar o cardiaca (1). Su frecuencia es de aproximadamente un 5\% de los pacientes con cirrosis. Por su localización es mas frecuente el derrame pleural derecho $(85,4 \%)$. Aunque en la mayoría de los casos se acompaña de ascitis significativa, el hidrotórax hepático se desarrolla, a veces, en su ausencia. Su 


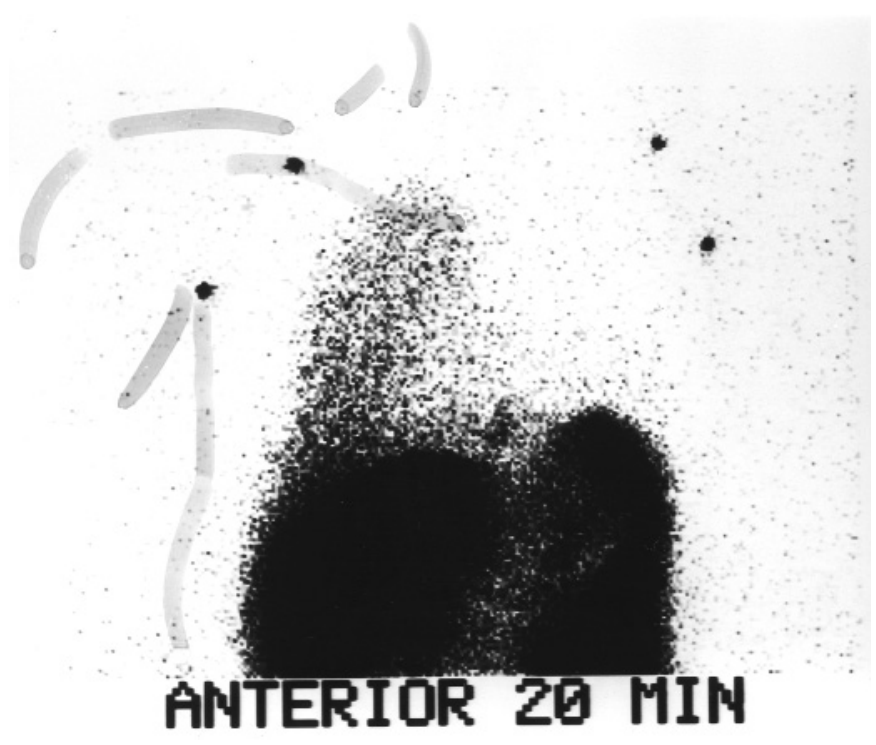

Fig. 1. Gammagrafía después de la administración de macroagregados de albúmina marcada con Tc99m a nivel intraabdominal. Se observa parte del radiotrazador en la cavidad torácica 20 minutos después de su administración lo que demuestra la comunicación peritoneo-pleural.

patogenia está relacionada con la existencia de defectos diafragmáticos los cuales hacen posible la transmisión peritoneo-pleural de líquido ascítico con las variaciones de la presión intratorácica (2). En la sintomatología predomina la disnea cuando el volumen de líquido pleural es grande. El diagnóstico de hidrotórax hepático es la mayoría de las veces fácil. En un paciente cirrótico con derrame pleural derecho en ausencia de enfermedad concomitante cardiopulmonar, el diagnóstico es muy probable. En los casos en los cuales existen dudas o para establecer el diagnóstico diferencial está indicada la realización de una toracocentésis, la composición bioquímica del líquido pleural es similar a la del líquido ascítico. Sin embargo, el diagnóstico definitivo se establece al demostrar la comunicación pleuroperitoneal usando una gammagrafía después de inyectar macroagregados de albúmina marcada con Tc-99m intraperitoneal (3). Aunque la especificidad de la prueba es del $100 \%$ la sensibilidad se ha documentado en $71 \%$ debido a la naturaleza intermitente de la comunicación y a la diferencia de presión entre el espacio pleural y la cavidad peritoneal. En cuanto al tratamiento, aunque el defecto diafragmático puede cerrarse espontáneamente, resolviendo así el derrame, lo normal es que persista, por lo que inicialmente se recomienda tratamiento conservador a base de diuréticos, restricción salina y realizando toracocentesis evacuadoras si es necesario. Si no hay respuesta a los diuréticos o el paciente no los tolera, requiriendo toracocentesis repetidas para controlar el derrame, se deben de considerar otras opciones. La colocación de un tubo de drenaje endotorácico está relativamente contraindicada ya que no resuelve el proceso subyacente y se asocia con diversas complicaciones como alteraciones hidroelectrolíticas e hipovolemia además de favorecer el desarrollo de infecciones. La pleurodesis química con tetraciclinas o talco no es efectiva. Los tratamientos mas agresivos son también los mas eficaces así la toracotomía para cerrar el defecto diafragmático (pleurodesis quirúrgica) sería el más efectivo, sin embargo este procedimiento presenta un riesgo muy alto en este tipo de pacientes con múltiples problemas médicos. Otra opción es realizar una derivación portosistémica (4), el objetivo de esta técnica es lograr una disminución de la presión portal, la cual es el origen y la responsable de que el hidrotórax hepático se perpetúe. En dos grandes series publicadas hasta la fecha, la mayoría de los pacientes a los que se les realizó esta técnica mejoraron completa o parcialmente del hidrotórax, $(5,6)$. Algunos autores señalan que el TIPS representa una mejora definitiva en el manejo del hidrotórax hepático y que su indicación es absoluta (4).

\section{J. M. Fernández Font, J. de Miguel Díez', V. Opio Maestro}

Servicios de Aparato Digestivo y 'Neumología del Hospital Universitario de Getafe. Getafe. Madrid

1. Strauss RM, Boyer TD. Hepatic Hydrothorax. Semin Liver Dis 1997; 17 : 227-32.

2. Lieberman FL, Hidemura R, Peters RL, Reynolds TB. Pathogenesisand reatment of hydrothorax complicating cirrhosis with ascites. Ann intern Med 1996; 64: 341-51.

3. Shih WJ, Ryo UY, Marsano L. Verification of peritoneo-pleural fluid communication and mediastinal lymph nodes by intraperitonel injection of technetium 99m albumin colloid. J Nucl Med 1989; 30: 559-60.

4. Burroughs, Patch. Tansjugular intrahepatic portosystemic shunt. Semin liver dis 1999; 19: 460-73.

5. Gordon FD, Anastopoulos HT, Crenshaw W. The successful treatment of symptomatic, refractory hepatic hydrothorax with transjugular intrahepatic portosystemic shunt. Hepatology 1997; 25: 1366-9.

6. Jeffries MA, Kazanjian S, Wilson MW, Punch J, Fontana RJ. Transjugular intrahepatic portosystemic shunt (TIPS) and liver transplantation in patients with refractory hepatic hydrothorax. Liver Transplant Surg 1998; 4: 416-23.

\section{Piomiositis en paciente diabética}

\section{Sr. Director:}

La piomiositis es una infección aguda del músculo esquelético frecuente en los trópicos y rara en climas templados. En éstos, se asocia a factores predisponentes como adicción a drogas por vía parenteral, infección por VIH, hepátopatía alcohólica, tratamiento con corticoides, diabetes mellitus y otras enfermedades que producen inmunosupresión. El microorganismo responsable más frecuente es Staphyloccocus aureus. Clínicamente se caracteriza por fiebre, dolor, y empastamiento muscular localizado. Presentamos un caso de Pyomiositis del músculo gastrocnemio derecho por Staphyloccocus aureus en una paciente diabética.

Mujer de 56 años de edad, con antecedentes de Diabetes Mellitus tipo 2 en tratamiento con Insulina, que consulta por dolor e inflamación en miembro inferior derecho (MID) de 15 días de evolución. En la exploración física presenta fiebre $38,5^{\circ}$ y aumento de volumen y temperatura en MID con empastamiento y dolor a la palpación en región gemelar posterior.

En las exploraciones complementarias destaca: leucocitos 11.700 con $65,3 \%$ neutrofilos, Hb: $9,1 \mathrm{grp} / \mathrm{dl}$, plaquetas: 676.000 ; VSG: 111, fibrinógeno: $940 \mathrm{mg} / \mathrm{dl}$. Glucosa, función renal, hepática y enzimas musculares normales. Hemocultivos x 3 y cultivo del absceso muscular: Staphyloccocus aureus meticilin sensible. Serologías VHB, VHC, VIH (1 y 2) negativos.

Estudios de imagen: Rx de MID: aumento de partes blandas. Ecografía musculoesquelética de MID: imagen hipoecoica ovoidea de 84 x $27 \mathrm{~cm}$ con algún área tenue de mayor ecogenicidad en su interior, de bordes bien definidos, de localización intramuscular compatible con hematoma o absceso muscular. Eco Doppler de MID: sin signos de trombosis venosa profunda (TVP).

Evolución: La paciente fue tratada con cloxacilina por vía 


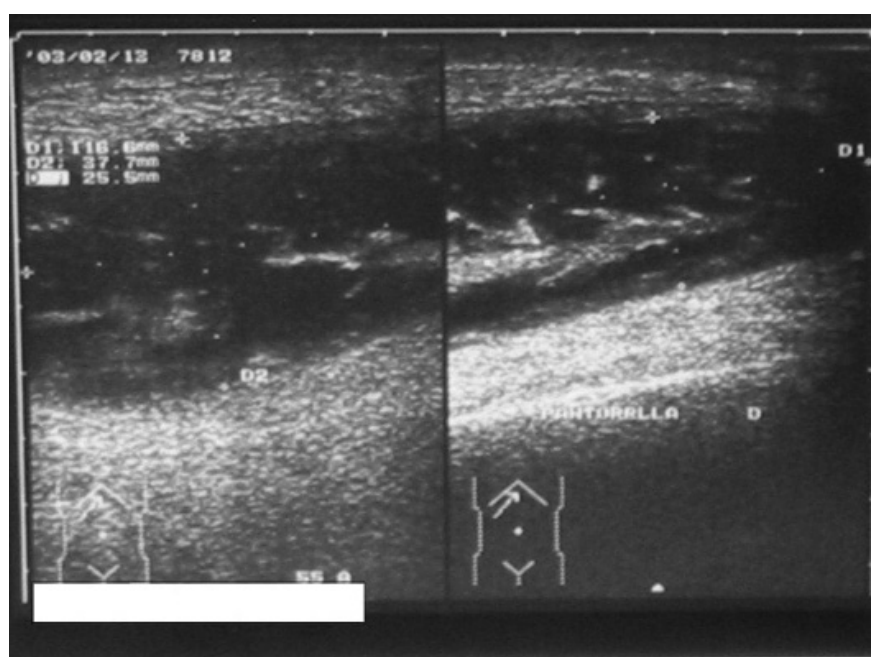

Fig. 1.

parenteral durante cuatro semanas y drenaje quirúrgico de 400 cc de líquido purulento con desaparición del cuadro clínico y recuperación funcional.

La piomiositis se describió por primera vez en 1885 por Scriba como una enfermedad endémica en los trópicos (1), se pensaba asociada a infecciones parasitarias o déficits nutricionales. Desde 1971, en que se describió por primera vez en Estados Unidos hasta nuestros días se ha objetivado un aumento en climas templados (2) aunque sigue siendo infrecuente (3) por lo que se requiere un alto índice de sospecha para su diagnóstico.

Las piomiositis pueden ser primarias o secundarias . En las formas primarias se acepta que el absceso muscular se forma a partir de una diseminación hematógena sobre un músculo previamente alterado, en condiciones normales es muy baja la incidencia de infección muscular en la sepsis estafilocócica. Existen factores predisponentes como diabetes mellitus, hepatopatía alcohólica, tratamiento con corticoides, enfermedades inmunosupresoras (leucemia, linfomas otros trastornos hematológicos) e infección por VIH entre otros.

En el caso de pacientes diabéticos, parece que se desarrollan alteraciones musculares y circulatorias que junto con la disfunción de los granulocitos y el deterioro de la inmunidad celular aumentan el riesgo de infección muscular.

El patógeno implicado con más frecuencia es Staphyloccocus aureus, seguido por Streptoccocus del grupo A, pero otros muchos microorganismos pueden causar esta infección $(4,5)$.

La clínica suele ser subaguda y en fase inicial sólo produce dolor muscular localizado. En la fase tardía aparecen signos de inflamación muscular, eritema, edema, fluctuación e impotencia funcional, fiebre y afectación del estado general. Las formas fulminantes son raras y cuando ocurren el microorganismo implicado con mayor frecuencia es Streptoccocus del grupo A. En un 40- 75\% de los casos, se afecta un solo músculo siendo los más frecuentes los músculos largos de miembros inferiores pero también se han descrito casos de afectación de músculos de la pared torácica o abdominal.

Entre las alteraciones analíticas destaca leucocitosis con neutrofilia, a diferencia de las formas tropicales, es rara la eosinofilia y aumento de la velocidad de sedimentación. No es frecuente la elevación de enzimas musculares a pesar de la extensa destrucción muscular. En la piomiositis no tropical la bacteriemia oscila entre un $5-35 \%$ (6).

Las técnicas de imagen como ecografía, TC, gammagrafía y RNM son útiles para identificar el número, tamaño, extensión, localización de los abscesos (7) y guiar la punción con aguja. En nuestro caso, la ecografía musculoesquelética fue de gran utilidad en la orientación diagnóstica al identificar una colección hipoe- coica con ecos en su interior, imagen característica de piomiositis (8), localizar y guiar la punción-aspiración para la obtención de muestras para el cultivo.

El diagnóstico microbiológico se basa en los hemocultivos y cultivo de la muestra del absceso muscular cuya sensibilidad es del $100 \%$ (9).

El diagnóstico diferencial incluye traumatismo muscular, TVP (en este caso fue el primer diagnóstico de sospecha), osteomielitis, celulitis , artritis séptica y tumores malignos.

El tratamiento es medico-quirúrgico, terapia antibiótica y drenaje quirúrgico de los abscesos; se han comunicado resultados favorables con drenaje por aspiración con aguja fina. De forma empírica se debe iniciar la administración intravenosa de penicilinas resistentes a betalactamasas por la elevada prevalencia de estafilococos resistentes a penicilinas; si se aísla Streptoccocus del grupo A cambiar a Penicilina G. El inicio del tratamiento con antibióticos se debe basar en la tinción de gram de las muestras obtenidas de los abscesos y posteriormente en el resultado del cultivo y antibiograma.

El pronóstico es favorable con tratamiento adecuado, la mortalidad oscila entre el 1-10\% dependiendo de la enfermedad de base, la rapidez del diagnóstico y la instauración del tratamiento.

\section{J. Jaras Hernández, J. González Polo, A. Gómez Lumbreras, R. Sánchez Garrido, A. Gordo Mejías, A. Noguerado Asensio}

Servicio de Medicina Interna V. Hospital General Universitario Gregorio Marañón. Cantoblanco. Madrid

1. Scriba J. Beitrag zur aetiologie der myositis acuta. Dtsch Z Chir 1885; 22: 497-502.

2. Levin MJ, Gardner P, Waldvogel FA. Tropical pyomyositis: An unusual infection due to Staphyloccocus Aureus. N Engl J Med 1971; 284: 196-8.

3. Das I, Jayatunga AP, Symonds JM. Pyomyositis: an unusual infection due to staphylococcus aureus. J R Coll Surg Edinb 1996; 41: 182-3.

4. Wang TK, Wong SS, Woo PC. Two cases of pyomyositis caused by Klebsiella pneumoniae and review of the literature. Eur J Clin Microbiol Infect Dis 2001; 20 (8): 576-80.

5. Gómez-Reino JJ, Aznar JJ, Pablos JL, Díaz-González F, Laffon A. Non tropical pyomyositis in adults. Semin Artritis Rheum 1994; 23: 396-405.

6. Patel SR, Olenginski TP, Perruquet JL, Harrington TM. Pyomyositis: Clinical features and predisposing conditions. J Rheumatol 1997; 24: 1734-1738.

7. Soler R, Rodríguez E, Aguilera C, Fernández R. Magnetic resonance imaging of pyomyositis in 43 cases. Eur J Radiol 2000; 35: 59-64.

8. Van Sonnenberg E, Wittich GR, Casola G, et al. Sonography of thigh abscess: detection, diagnosis and drainage. AJR 1987;149: 769.

9. Jiménez-Mejías ME, Lozano de León F, Alfaro-García MJ, FernándezLópez A, Jiménez-Ocaña C, Cañas García-Otero E, Pachón-Díaz J. Piomiositis por Staphylococcus aureus. Med Clin (Barc) 1992; 99: 201-205.

\section{Artritis tuberculosa}

\section{Sr. Director:}

Hemos leído con interés el trabajo de Rubio Barbón y cols. "Artritis tuberculosa de tobillo" (1). Entre los múltiples aspectos interesantes comentados por los autores, destaca el retraso en el diagnóstico de esta enfermedad. Sin embargo, el caso aportado presentaba una evolución previa al diagnóstico de 6 meses, frente a los 12-18 recogidos en otras series (1). En los últimos años hemos atendido a dos pacientes con una larga evolución y secuelas por esta infección.

Caso 1: Varón de 53 años de edad, ex-fumador, sin otros antecedentes clínicos relevantes, con dolor e inflamación en rodilla 


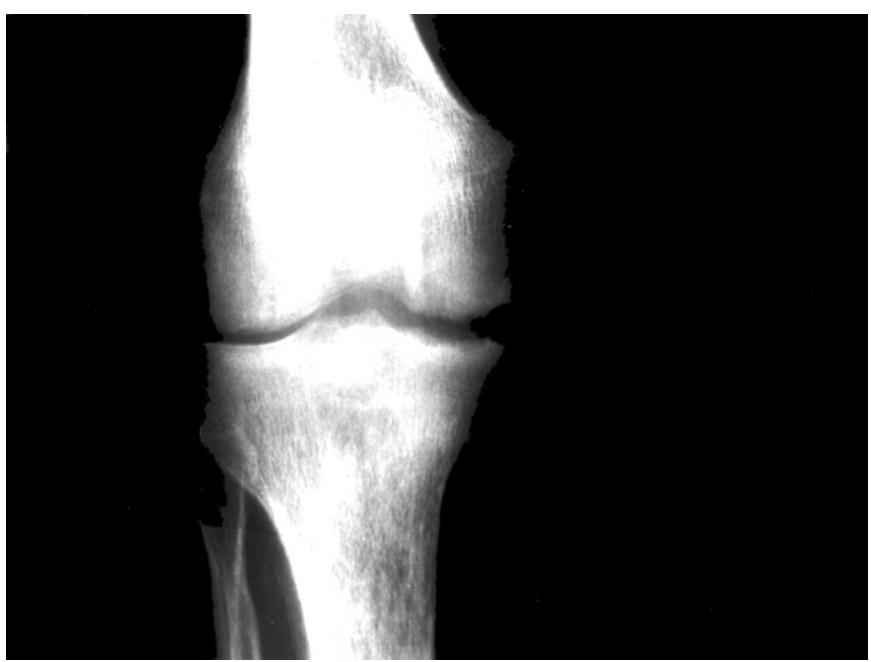

Fig. 1.

derecha de tres años de evolución. Se le practicó una artroscopia, objetivándose una lesión de menisco, y se realizó una resección parcial de menisco. El dolor del paciente empeoró precisando mórficos. Dos años después del inicio de los síntomas, desarrolló una fístula con exudación. Dos meses antes de acudir a consulta, se realizó una biopsia sinovial, encontrándose una sinovitis crónica granulomatosa. Además creció $M$. tuberculosis, y fue enviado a la consulta de Enfermedades Infecciosas. El paciente presentaba inflamación y rigidez de rodilla derecha, apreciándose exudación sobre cicatriz quirúrgica. El cultivo de este exudado fue positivo para M. tuberculosis. En los datos analíticos destacaba una PCR de $18 \mathrm{mg} / \mathrm{L}$, y una VSG de $91 \mathrm{~mm} / \mathrm{h}$. La radiografía de tórax fue normal, y en la radiografía de rodilla era evidente la destrucción de la interlínea articular y geodas (Fig. 1). Se inició tratamiento con isoniacida, rifampicina y piracinamida. El cultivo del exudado permaneció positivo durante 3 meses, y la fístula cerró cinco meses después del inicio de la terapia. Esta se mantuvo durante 12 meses, con una importante mejoría, sin precisar analgesia, y con normalización de la VSG y de la PCR. No obstante el paciente presenta graves secuelas en la funcionalidad de la articulación.

Caso 2: Varón de 84 años de edad, con antecedentes de hábito tabáquico, etílico y EPOC, en tratamiento con broncodilatadores. Veinte años antes fue diagnosticado de un absceso en muslo derecho, y de una lesión lítica en fémur derecho. El absceso fue drenado, y en los cultivos habituales creció un estafilococo coagulasa negativo. Un año antes ingresó por una neumonía en lóbulo inferior derecho. Las baciloscopias de esputo fueron negativas, y evolucionó favorablemente con amoxicilina-clavulánico y con resolución de los hallazgos radiológicos. En el último año había sufrido reagudizaciones bronquiales por lo que recibió esteroides sistémicos. Seis meses antes ingresa por un absceso en muslo derecho de $20 \times 10 \mathrm{~cm}$, que fue drenado quirúrgicamente observándose pus con grumos blanquecinos. En los cultivos habituales creció $S$. aureus, y se practicó una RNM apreciándose datos de osteomielitis del trocánter mayor, cuello y diáfisis femoral derecha, así como una colección que afectaba fundamentalmente al músculo vasto interno. En la analítica destacaba: hemoglobina 11 gr/dl, PCR de $25 \mathrm{mg} / \mathrm{L}$, y una VSG de $60 \mathrm{~mm}$. Tras la consulta con la Unidad de Enfermedades Infecciosas se decidió limpieza quirúrgica, y toma de muestras para cultivo y examen histológico. Las baciloscopias fueron negativas pero se observó crecimiento de $M$. tuberculosis en el exudado, en el tejido óseo y en las muestras de músculo. En el examen histológico del hueso se observaron granulomas necrotizantes. Fue tratado con isoniacida, rifampicina y piracinamidaa durante un año, con buena evolución clínica y radiológica, así como normalización de la PCR y de la VSG.

Estos casos, así como los aportados en la literatura muestran que la tuberculosis osteoarticular es una entidad que debe considerarse, incluso en los pacientes sin afectación pulmonar. Así mismo puede encontrarse en enfermos con una larga evolución y con un curso clínico fluctuante. En los casos descritos aquí se administraron terapias específicas prolongadas, aunque tratamientos más breves tal vez también pueden ser eficaces $(1,2)$.

Afortunadamente en los últimos años se han realizado esfuerzos y avances para el control de la tuberculosis, pero para su diagnóstico seguimos precisando de un alto índice de sospecha (3). Los casos aportados demuestran que el diagnóstico de la tuberculosis osteoarticular no es fácil, se acompaña en ocasiones de un importante retraso en su detección, con secuelas importantes y evitables.

\section{A. Chocarro Martínez, I. García García, A. González López}

Servicio de Medicina Interna. Unidad de Enfermedades Infecciosas. Hospital Virgen de la Concha. Zamora

1. Rubio Barbón S, Rodríguez Cocina B, Suárez del Villar Acebal R, Calvo Rodríguez CE, Villar López A, Escalada Rodríguez P, et al. Artritis tuberculosa de tobillo. An Med Interna (Madrid) 2004; 21: 444-446.

2. Haas DW, Mycobacterial diseases. In Mandell GL, Bennet JE, Dolin R. editores. Principles and practice of infectious diseases. 5nd ed.Philadelphia: Churchill Livingstone; 2000. p. 2576-2607.

3. Puerto Alonso JL, García-Martos P, Marín Casanova P, Vega Elías J, Mira Gutiérrez J. Valoración de un programa de prevención y control de la tuberculosis. Enferm Infecc Microbiol Clin 2002; 20: 150-3.

\section{Cuerpo extraño en la luz endobronquial de origen post-traumático}

\section{Sr. Director:}

A propósito del artículo publicado en su revista acerca de una condensación pulmonar en un adulto tras una consulta con un odontólogo (1), dada la incidencia de la existencia de cuerpos extraños en el interior del árbol bronquial (2-4), especialmente escasa en el caso del adulto $(5,6)$, exponemos nuestra experiencia sobre la impactación dental endobronquial, secundaria en esta ocasión a una etiología menos predecible como es el traumatismo torácico.

Paciente de 45 años de edad que es remitido a la Unidad de Cuidados Intensivos tras sufrir un accidente de tráfico. Ingresa intubado y conectado a ventilación mecánica. En la exploración física se aprecia hipoventilación en hemitórax derecho, siendo el resto de la exploración física compatible con la normalidad. Se procede a realizar un estudio radiológico simple de tórax donde se aprecia la existencia de una atelectasia del hemitórax derecho en el contexto de un traumatismo torácico con la visualización de dos cuerpos extraños de densidad radioopaca (como se muestra en la Figura 1). Debido a persistencia de alteraciones en la gasometría pese a encontrarse bajo ventilación mecánica, se realiza una TC pulmonar de modo urgente, hallándose dos piezas dentarias a nivel endobronquial. Posteriormente se procedió a extracción de las mismas mediante fibrobroncoscopia flexible. Se trata- 


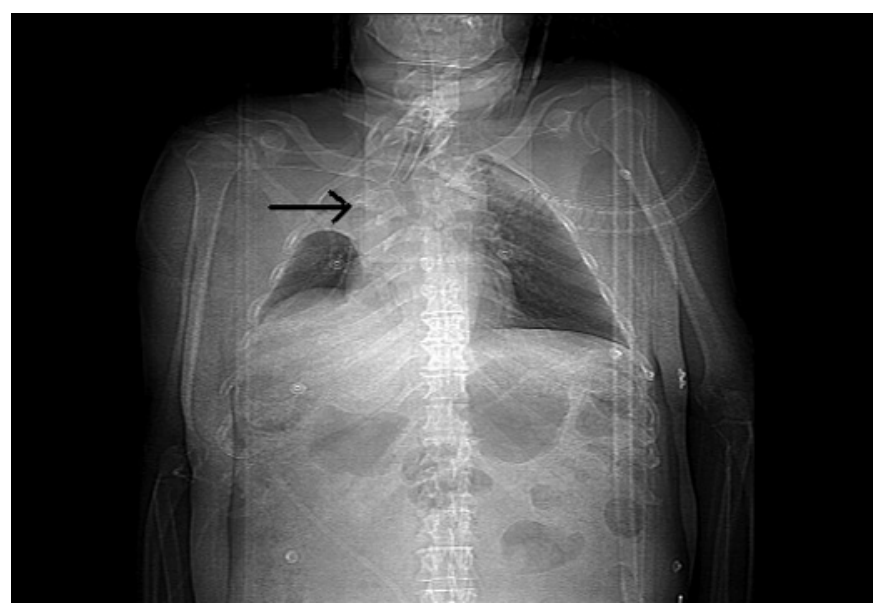

Fig. 1.

ba por tanto de una atelectasia postraumática por impactación de 2 piezas dentarias a nivel endobronquial.

Ante la existencia de un politraumatismo, y especialmente en el traumatismo torácico que se acompaña de alteraciones en la exploración física, en el intercambio respiratorio así como en la radiografía de tórax es importante sospechar la presencia de impactación de un cuerpo extraño (piezas dentarias) en el árbol bronquial, producto de la deglución de los mismos bien por la violencia con la que se produjo el traumatismo, bien por maniobras "traumáticas" derivadas de la intubación orotraqueal urgente en el lugar del accidente. Además, la realización de una TC torácica resulta imprescindible para filiar la etiología de la atelectasia $(7,8)$, lo que permite evitar la yatrogenia derivada de la corrección de los parámetros respiratorios mediante ventilación mecá- nica, e iniciar el tratamiento, que en este caso consiste en la extracción de los cuerpos extraños con fibrobroncoscopia flexible $(1,6,9)$, resolviendo al mismo tiempo la atelectasia y las alteraciones en el intercambio gaseoso.

\section{B. Obón Azuara, I. Gutiérrez Cía, P. Sánchez Santos ${ }^{1}$, C. Sánchez Polo, B. Villanueva Anadón ${ }^{2}$}

Servicio de Medicina Intensiva. 'Servicio de Radiología. Hospital Obispo Polanco. Teruel. ${ }^{2}$ Servicio de Medicina Intensiva. Hospital Clínico Universitario. Zaragoza

1. Guerra del Barrio E., Ojer Tsakidiru D., Vallina García J. Condensación pulmonar en el adulto tras consulta con odontólogo. An Med Interna (Madrid) 2004; 21: 514-515.

2. Pritt B, Harmon M, Schwartz M, Cooper K. A tale of three aspirations foreign bodies in the airway. J Clin Pathol 2003; 56: 791-4.

3. Siddiqui MA, Banjar AH, Al-Najjar SM, Al-Fattani MM, Aly MF. Frequency of tracheobronchial foreign bodies in children and adolescents. Saudi Med J 2000; 21: 368-71.

4. Friedman EM. Tracheobronchial foreign bodies. Otolaryngol Clin North Am 2000; 33: 179-85.

5. Baharloo F, Veyckemans F, Francis C, Biettlot MP, Rodenstein DO. Tracheobronchial foreign bodies: presentation and management in children and adults. Chest 1999; 115: 1357-62.

6. Limper AH, Prakash UB. Tracheobronchial foreign bodies in adults. Ann Intern Med 1990; 112: 604-9.

7. Zissin R, Shapiro-Feinberg M, Rozenman J, Apter S, Smorjik J, Hertz M. $\mathrm{CT}$ findings of the chest in adults with aspirated foreign bodies. Eur Radiol 2001; 11: 606-11.

8. Seo JB, Song KS, Lee JS, Goo JM, Kim HY, Song JW, et al. Broncholithiasis: review of the causes with radiologic-pathologic correlation. Radiographics 2002; 22: S199-213.

9. Liebler JM, Markin CJ. Fiberoptic bronchoscopy for diagnosis and treatment. Crit Care Clin 2000; 16: 83-100. 